\title{
AVALIAÇÃO DE FURANOCUMARINAS COMO INIBIDORES DA FOTOSSÍNTESE ATRAVÉS DE ENSAIOS DE FLUORESCÊNCIA DA CLOROFILA $a^{\#}$
}

\author{
Olívia Moreira Sampaio e Maria Fátima das Graças Fernandes da Silva* \\ Departamento de Química, Universidade Federal de São Carlos, CP 676, 13560-970 São Carlos - SP, Brasil \\ Thiago André Moura Veiga \\ Instituto de Ciências Ambientais, Químicas e Farmacêuticas, Universidade Federal de São Paulo, R. Prof. Artur Riedel, 275, \\ 09972-270 Diadema - SP, Brasil \\ Beatriz King-Díaz e Blas Lotina-Hennsen \\ Departamento de Bioquímica, Facultad de Química, Universidad Nacional Autónoma de México, México D. F. 04510, México
}

Recebido em 15/5/12; aceito em 18/9/12; publicado na web em 26/10/12

\begin{abstract}
EVALUATION OF FUROCOUMARINS AS PHOTOSYNTHETIC INHIBITOR BY CHLOROPHYLL $a$ FLUORESCENCE ASSAY. The evaluations of Chorophyll $a$ fluorescence emitted by superior plants carry structural information and photosynthetic apparatus function. Quantitative analysis apparatus of fluorescence kinetic were measured by energy flows (ABS), (TR), (ET) and (DI), known as phenomenological phenomena of OJIP test. Four furocoumarins were isolated from Ruta graveolens (Rutaceae), and chorophyll $a(\mathrm{Chl} a)$ fluorescence assays were performed with these compounds to evaluate the photosynthesis inhibition potential. This test was realized in spinach`s leaf discs and in Lolium perenne leaves. The results indicated the herbicide potential mainly for bergapten and chalepin.
\end{abstract}

Keywords: Chl $a$ fluorescence; furocoumarins; "JIP-test".

\section{INTRODUÇÃo}

Evolução e pressão de seleção são processos que as espécies vegetais suportam constantemente ao redor do mundo. Muitas plantas, especialmente as daninhas, apresentam uma ampla variabilidade genética, que lhes permite sobreviver em uma diversidade de condições ambientais. Nos últimos anos, o controle das plantas daninhas tem sido realizado basicamente pelo uso de herbicidas. ${ }^{1,2}$

Além dos perigos aos seres humanos, nos aspectos ocupacionais, alimentares e de saúde pública, sabe-se que a introdução de agrotóxicos no ambiente pode provocar efeitos indesejáveis, tendo como consequência mudanças no funcionamento do ecossistema afetado. O Brasil é um país altamente agrícola, e o consumo anual de agrotóxicos no país tem sido superior a 300 mil $\mathrm{t}$ de produtos comerciais. ${ }^{2}$

Os herbicidas inibidores da fotossíntese são amplamente empregados na agricultura brasileira nas culturas de Zea mays (milho), Saccharum officinarum (cana-de-açúcar), Glycine max (soja), na cultura de frutas, hortaliças, entre outras. Esta classe de herbicidas é uma das mais importantes em todo o mundo. A taxa de fixação de $\mathrm{CO}_{2}$ declina poucas horas após o tratamento com este tipo de herbicida e eles não possuem problemas de volatilização e apresentam baixa toxicidade para mamíferos. ${ }^{1,2}$

Os pigmentos, as proteínas e outras substâncias químicas envolvidas na reação da fotossíntese estão localizados nos cloroplastos. Em condições normais, sem a interferência de inibidores fotossintéticos, durante a fase fotoquímica, a energia luminosa capturada pelos pigmentos (clorofila e carotenoides) é transferida para um "centro de reação" especial (P680), gerando um elétron “excitado". Este elétron é transferido para uma molécula de quinona localizada na membrana tilacoide do cloroplasto $\left(\mathrm{Q}_{A}\right)$. A quinona $\mathrm{A}$ transfere o elétron para outra molécula de plastoquinona (PQ), que se reduz a plastoquinol, chegando no citocromo $\mathrm{b}_{6} f$, em seguida, até a plastocianina (PC),

*e-mail: dmfs@ufscar.br

\#Artigo em homenagem ao Prof. Otto R. Gottlieb (31/8/1920-19/6/2011) localizadas na mesma proteína. ${ }^{3}$ A captura de dois prótons a partir do estroma é também requerida para a formação do plastoquinol. A difusão do platoquinol ocorre através da camada lipídica da membrana tilacoidal ao complexo citocromo $\mathrm{b}_{6} f$, onde dois elétrons são transferidos ao complexo proteico do fotossistema I (FSI) e dois prótons são liberados ao espaço intratilacoide. Consequentemente, a transferência de elétrons da molécula de água ao $\mathrm{b}_{6} f$ está associada com a geração de um gradiente de prótons através da membrana, devido a uma diferença de potencial eletroquímico, resultante da oxidação da água pelo PSII no lado do lumen da membrana tilacoide e a ciclo redução-oxidação da plastoquinona. ${ }^{4}$ A captura de prótons envolvida na redução de $\mathrm{NADP}^{+}$no estroma também contribui para a criação de uma diferença de potencial transmembrana que pode ser usada para guiar a síntese de ATP, através do fator acoplamento. A ferredoxina transfere elétrons para o $\mathrm{NADP}^{+}$e a reação é catalisada pela redutase de ferredoxina-NADP ${ }^{+}$, uma flavoproteína solúvel, com um grupo de flavina adenina dinucleotídeo protético (FAD). O FAD oxidado aceita dois elétrons e dois prótons a partir de duas moléculas de ferredoxina reduzida para formar $\mathrm{FADH}_{2}$, e essa coenzima transfere um hidreto para $\mathrm{NADP}^{+}$para reduzi-lo a NADPH. ${ }^{4}$

Existem muitas metodologias para o estudo da fotossíntese, porém a grande maioria requer o desagregamento do material fotossintético para deixá-lo em seus componentes moleculares básicos, ou seja, a maioria dos estudos é in vitro. Contudo, existe um grupo de metodologias que permite estudar detalhes da fotossíntese sem destruir nenhum tecido fotossintético, baseado na quantificação da emissão da fluorescência da clorofila $a{ }^{5}$ Essas técnicas por serem indiretas, precisas, econômicas, rápidas e não destrutivas, nos últimos anos têm levado a uma grande variedade de estudos in vivo do aparato fotossintético em diversos sistemas biológicos. A principal vantagem é que a medida da fluorescência oferece um grande número de informações sobre os sistemas biológicos..$^{5-8} \mathrm{~A}$ metodologia que permite o maior número de informações é o test-JIP, o qual consiste na análise dos transientes da fluorescência da clorofila $a$, traduzindo as informações que se encontram nos parâmetros biofísicos que 
quantificam o comportamento dos fotossistemas II e I (FSII e FSI) ${ }^{8}{ }^{813}$ Essa metodologia fornece informações do comportamento do aparato fotossintético, estrutura, conformação e funcionalização em qualquer estado fisiológico. ${ }^{14}$

A técnica está baseada em três suposições básicas: os centros reativos (RCs) de FSII são unicamente definidos pelo processo redox do aceptor primário do FSII, a quinona $A\left(Q_{A}\right)$; quando $Q_{A}$ é reduzida em um RC, o mesmo se encontra fechado e a fluorescência da Chl $a$ é alta; enquanto $\mathrm{Q}_{\mathrm{A}}$ está no estado oxidado, o RC está aberto e o sinal da fluorescência da antena é atenuado; à temperatura ambiente, a presença da clorofila $a$ em plantas, algas e cianobactérias se encontra na região de 680 e $740 \mathrm{~nm}$ e é estimulada principalmente pelo FSII. ${ }^{8,9,14}$ Os dados de fluorescência podem oferecer informações de outros parâmetros também envolvidos na avaliação da eficiência do aparato fotossintético. Todas as variáveis avaliadas são cálculos quânticos baseados nos quatro acontecimentos principais da fotossíntese [absorção da energia $(A B S)$, aprisionamento da energia $(T R)$, transporte de elétrons $(E T)$ e receptor final $(R E)]$.

A fluorescência da Chl $a$ pode ser considerada como uma investigação intríseca do sistema de fotossíntese e da intensidade da fluorescência como medida direta das atividades do FSII. A partir de dados armazenados, durante o primeiro segundo de aquisição do experimento, os valores seguintes são selecionados para serem utilizados pelo test-JIP para o cálculo das várias expressões fenomenológicas e biofísicas, ${ }^{8}$ que conduzem à descrição dinâmica de uma amostra da fotossíntese em um determinado estado fisiológico. Este comportamento é quantificado por meio desses vários parâmetros funcionais e estruturais que são derivados dos transientes da fluorescência, os quais são analisados de acordo com a teoria de fluxo de energia em biomembranas. ${ }^{12,14}$ Os parâmetros funcionais calculados por este ensaio, chamado de test-JIP, são específicos (centro de reação-RC) e fenomenológicos (seção transversal-CS), medindo o acúmulo de energia absorvida (TR) e conversão de energia de excitação para a cadeia transportadora de elétrons $(\mathrm{ET}){ }^{8}$

Dando continuidade aos estudos sobre a interação de produtos naturais com os sítios da fotossíntese,,${ }^{6,7,15,16}$ o potencial herbicida das furanocumarinas psoraleno, bergapteno, chalepensina e chalepina foram avaliados dentro da cadeia transportadora de elétrons.

\section{PARTE EXPERIMENTAL}

\section{Estudo fitoquímico}

O material vegetal foi coletado em 27/2/2008 no Sítio Akai, localizado na Rodovia Dom Pedro I, km 83, no município de Atibaia - SP. As partes aéreas da planta Ruta graveolens foram extraídas e preparados os extratos vegetais. Estes foram fracionados por meio de cromatografia líquida via camada delgada, partição e exclusão.

\section{Estudos da fluorescência da clorofila $a(\mathrm{Chl} a)$ em discos foliares de Spinacia oleracea $\mathrm{L}$.}

De folhas de $S$. oleracea $\mathrm{L}$. foram feitos 10 discos com diâmetro de $1 \mathrm{~cm}$ cada e colocados em placas de Petri $(90 \times 10 \mathrm{~cm})$ contendo $20 \mathrm{~mL}$ do meio Krebs "modificado": $\mathrm{NaCl}$ (115 mM), $\mathrm{KCl}$ (5,9 mM), $\mathrm{MgCl}_{2}(1,2 \mathrm{mM}), \mathrm{KH}_{2} \mathrm{PO}_{4}(1,2 \mathrm{mM}), \mathrm{Na}_{2} \mathrm{SO}_{4}(1,2 \mathrm{mM}), \mathrm{CaCl}_{2}(2,5$ $\mathrm{mM})$ e $\mathrm{NaHCO}_{3}(25 \mathrm{mM})$ ajustado a $\mathrm{pH} 7,4$. As placas contendo os discos permaneceram em agitação $(130 \mathrm{rpm})$ por um fotoperíodo de $12 \mathrm{~h}$ à temperatura ambiente $\left(26^{\circ} \mathrm{C}\right)$. Após esse período, foram adicionadas aos discos foliares alíquotas das substâncias (150 e 300 $\mu \mathrm{M}$ ) isoladas de Ruta graveolens e para o controle adicionou-se os mesmos volumes de dimetil sulfóxido (DMSO). Após um período de aproximadamente $6 \mathrm{~h}$ de incubação, os discos permaneceram por

30 min no escuro e, em seguida, foram realizadas as medidas de fluorescência da Chl $a$ com um Hansatech Handy PEA (Plant Effiecient Analyzer) ${ }^{8,9,17} \mathrm{O}$ processamento dos dados foi feito com o programa Biolyzer_HP3, onde foram avaliados 19 parâmetros fotossintéticos e as curva polifásicas transientes. Para esse experimento foram realizadas 10 replicatas.

\section{Estudos da fluorescência da clorofila $a(\mathrm{Chl} a)$ em folhas de Lolium perenne}

Para a realização deste experimento, primeiramente cultivaram-se plantas da espécie $L$. perenne. Duzentas sementes foram selecionas para cada vaso e foram plantadas com terra previamente esterilizada. Estas foram mantidas em estufa a $25-30^{\circ} \mathrm{C}$ por 15 dias para crescimento. Após o período estabelecido para crescimento (15 dias), as plantas de $L$. perenne foram selecionadas por tamanho similar e foram borrifadas soluções dos compostos $(150$ e $300 \mu \mathrm{M})$. A alíquota de cada composto foi solubilizada em uma solução de Tween-20 (0,05\%). O grupo de plantas controle foi borrifado com Tween e DMSO. Foram efetuadas as medidas de emissão da fluorescência da Chl $a$ in vivo com auxílio de um Hansatech Handy PEA (Plant Effiecient Analyzer), nos períodos de 24, 48 e $72 \mathrm{~h}$. Antes de cada medida, as plantas eram deixadas em repouso, no escuro, por $30 \mathrm{~min} .{ }^{18}$ Para as medidas de fluorescência e para o processamento dos dados utilizou-se o Biolyzer_HP3 e os mesmos parâmetros fotossintéticos foram avaliados. Todas as medidas foram realizadas em triplicata e todas as determinações foram estabelecidas por comparação ao controle. Para o preparo das soluções foi utilizada água destilada.

\section{RESULTADOS E DISCUSSÃO}

Os ensaios de fluorescência da Ch $a$ em discos foliares de $S$. oreacea (semi "in vivo") e em plantas de L. perenne (in vivo) foram realizados com as quatro substâncias em duas concentrações diferentes. A Figura 1 mostra as quatro furanocumarinas [psoraleno (1); chalepensina (2); bergapteno (3); chalepina (4)] avaliadas neste trabalho. As substâncias $\mathbf{1}$ e $\mathbf{2}$ em disco foliares (Figura 2) apresentaram um aumento de aproximadamente $45 \%(150 \mu \mathrm{M})$ no parâmetro índice de desempenho $\mathrm{PI}\left({ }_{A B S}\right)$. O PI $\left({ }_{A B S}\right)$ é uma das principais variáveis avaliadas, pois é a mais sensível para a detecção e quantificação de danos causados às plantas, e relaciona a eficiência de absorção, captura e transferência de energia de excitação do FSII, proporcionando uma melhor definição do grau de efeito do ambiente estressante. ${ }^{17-19}$
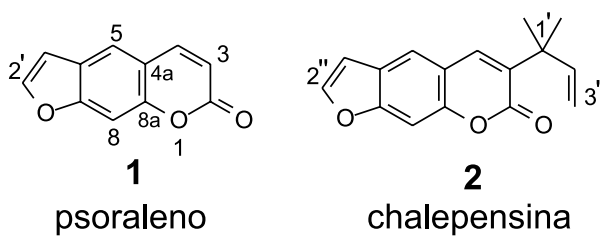<smiles>COc1c2ccoc2cc2oc(=O)ccc12</smiles>

3

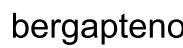

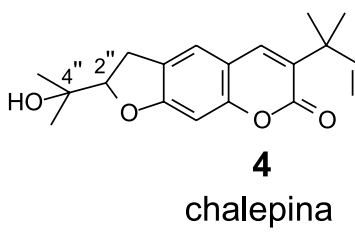

Figura 1. Estrutura das furanocumarinas ensaiadas

Na busca pelo fator que influenciou essa alteração para as substâncias $\mathbf{1}$ e 2, notou-se que um parâmetro com relação à seção transversal da amostra (CS) fornecia informação suficiente para sugerir o efeito 


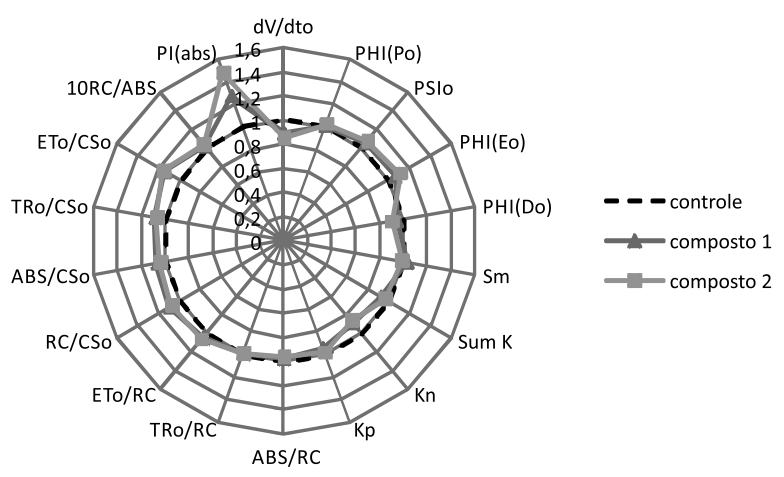

Figura 2. Gráfico de radar dos efeitos das substâncias 1 e 2 (150 $\mu$ M) nas variáveis da fluorescência Chl a em discos foliares de espinafre, calculados através da curva OJIP

direto sobre os transportes de elétrons. A variável transporte de elétrons por seção transversal $\left(\mathrm{Et}_{0} / \mathrm{CS}_{0}\right)$ apresentou um aumento de $20 \%$ $(150 \mu \mathrm{M})$ sugerindo dessa forma que o efeito apresentado pelo $\mathrm{PI}\left({ }_{A B S}\right)$ foi verificado no transporte de elétrons. Essa variação observada é reduzida para as furanocumarinas $\mathbf{1}$ e $\mathbf{2}$, quando comparada a outros herbicidas conhecidos como inibidores da fotossíntese. Em alta concentração $(300 \mu \mathrm{M})$, não foram observados resultados significativos comparando com o controle $(<20 \%)$, Figura 3.

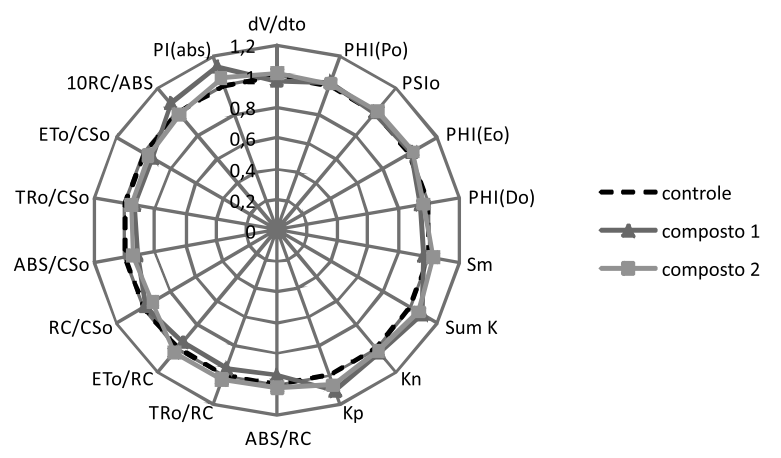

Figura 3. Gráfico de radar do efeito das substâncias 1 e 2 (300 $\mu$ M) nas variáveis da fluorescência Chl a em discos foliares de espinafre, calculados através da curva OJIP

A substância 3, na fluorescência em disco foliares (Figura 4), apresentou um efeito diferenciado. Em baixa concentração não foram observados resultados significativos $(<20 \%)$, contudo, em concentrações mais elevadas, pôde-se verificar um efeito diretamente ligado ao transporte de elétrons. O índice de desempenho $\mathrm{PI}\left({ }_{A B S}\right)$ diminuiu em aproximadamente $60 \%$ na concentração de $300 \mu \mathrm{M}$, enquanto que o parâmetro mudança da fluorescência variável relativa em função do tempo (dV/dto) teve um aumento de $40 \%$, indicando que o aparato fotossintético, exclusivamente no FSII, está sofrendo um estresse. $\mathrm{Na}$ busca pelo fator que influenciou essa alteração, notou-se que o parâmetro de RC não apresentou variação significativa, entretanto, os parâmetros com relação à seção transversal da amostra (CS) forneceram informações suficientes para sugerir seu efeito direto sobre os transportes de elétrons.

Os parâmetros transporte de elétrons por seção transversal $\left(\mathrm{ET}_{0} /\right.$ $\left.\mathrm{CS}_{0}\right)$, taxa máxima de energia bloqueada por seção transversal $\left(\mathrm{TR}_{0} /\right.$ $\mathrm{CS}_{0}$ ) e densidades de centros de reação por seção transversal ( $\mathrm{RC} /$ $\mathrm{CS}_{0}$ ) sofreram diminuição de 40, 20 e $20 \%$ na concentração de 300 $\mu \mathrm{M}$, respectivamente, indicando que a energia absorvida nessas seções foi reduzida. Isto ocorreu pelo fato de que a substância 3 inibiu o transporte de elétrons e, não havendo necessidade de transportá-los, portanto, o gasto de energia no processo foi reduzido. Por outro lado,

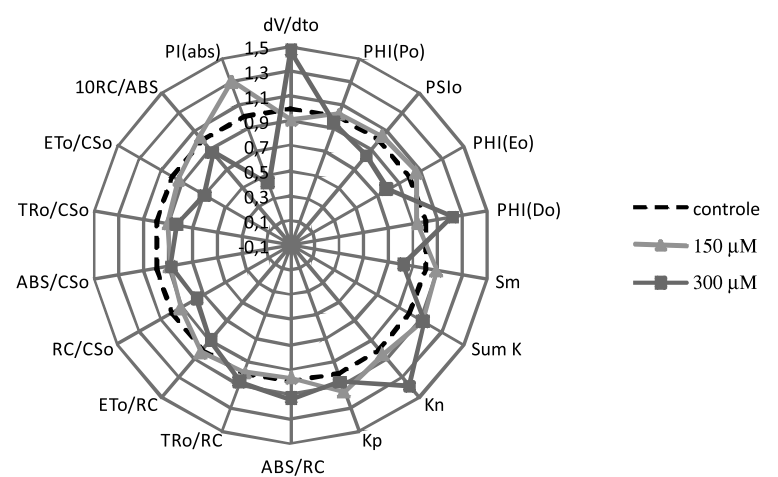

Figura 4. Gráfico de radar do efeito das substâncias 3 (150 e 300 M) nas variáveis da fluorescência Chl a em discos foliares de espinafre, calculados através da curva OJIP

as variáveis de rendimento quântico: a probabilidade, $\mathrm{t}=0$, de um excitón aprisionado mover um elétron pela cadeia transportadora de elétrons após Qa- (PSIo) e o rendimento quântico do transporte de elétrons (PHI(Eo)) diminuíram 20\% na mesma concentração, o que reafirma que a probabilidade de ocorrer fluxo de elétrons no interior de FSII diminuiu.

A energia absorvida durante o processo foi liberada na forma de calor e na transferência para outras moléculas, como demonstra a constante "de excitação" não fotoquímica $(\mathrm{K} n)$, que aumentou $40 \%$ durante o processo. A variável $\mathrm{PHI}(\mathrm{Do})$ [rendimento quântico $(\mathrm{t}=0)$ da energia de dissipação] aumentou em aproximadamente $20 \%$, o que indica a liberação de energia na forma de calor, afirmando que dos $40 \%$ da liberação não fotoquímica mencionada, aproximadamente $20 \%$ foram exclusivamente na forma de calor para o meio.

Para corroborar os resultados, o aparecimento de uma banda $\mathrm{J}$ ( $2 \mathrm{~ms}$ ) foi observada na concentração de $300 \mu \mathrm{M}$ (Figura 5). Através desta informação, pode-se sugerir que o composto atua no FSII, ligando-se ao pool de quinonas. Comparando ensaios in vitro e em semi in vivo observou-se que o mesmo não apresentou inibição no transporte de elétrons; isso ocorreu porque as medições dos transportes in vitro foram realizadas em baixas concentrações.

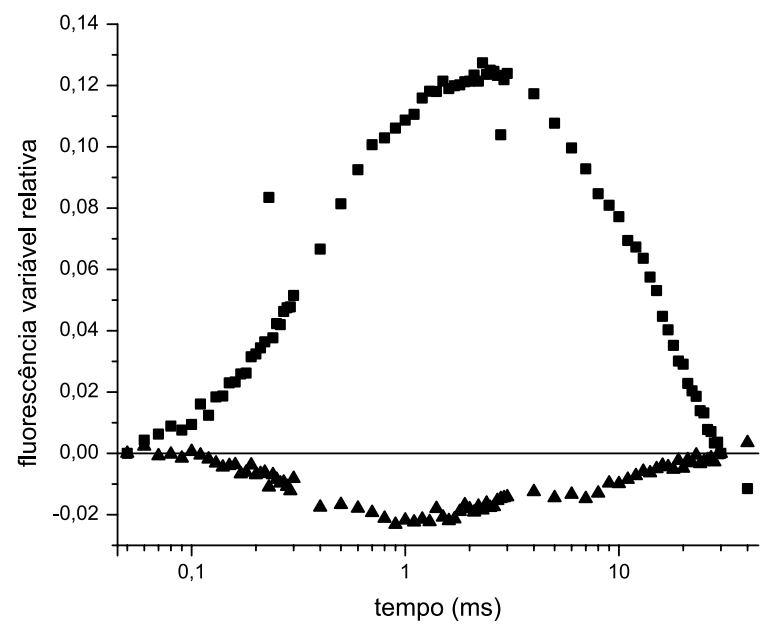

Figura 5. Bandas transientes da curva de emissão de fluorescência da Chl a (OJIP) para a substância 3 (А150 $\mu \mathrm{M} ; \mathbf{\square} 300 \mu \mathrm{M})$

A substância 4 mostrou resultados significativos na concentração de $300 \mu \mathrm{M}$ (Figura 6). Os parâmetros que variaram significativamente (>20\%) foram: $\mathrm{PI}\left({ }_{A B S}\right)$ diminuiu $60 \%$, enquanto o $\mathrm{dV} / \mathrm{dt}_{0}$ aumentou $40 \%$, demonstrando que a substância afetou o bom funcionamento da fotossíntese. Os parâmetros $\mathrm{TR}_{0} / \mathrm{CS}_{0},\left(\mathrm{ABS} / \mathrm{CS}_{0}\right)$ número de fótons 
absorvidos por seção transversal, $\mathrm{RC} / \mathrm{CS}_{0},\left(\mathrm{ET}_{0} / \mathrm{RC}\right)$ transporte de elétrons por centro de reação e as variáveis $\mathrm{PSI}_{0}$ e $\mathrm{PHI}\left(\mathrm{E}_{0}\right)$ diminuíram $20 \%$, demonstrando que houve dano no aparato fotossintético, no transporte de elétrons. Observou-se um aumento nas variáveis $\mathrm{K} n$ e PHI(D0) rendimento quântico $(\mathrm{t}=0)$ da energia de dissipação de 50 e $20 \%$, respectivamente; isto implica que a energia que foi absorvida durante o processo foi liberada na forma de calor ou na transferência para outras moléculas. Verificou-se uma banda transiente da curva polifásica OJIP em $2 \mathrm{~ms}$, a banda J, na concentração mais alta do experimento, evidenciando que a ação do composto está no lado aceptor de FSII $\left(\mathrm{Q}_{\mathrm{A}}{ }^{+}-\mathrm{Q}_{\mathrm{A}}{ }^{-}\right)$(Figura 7).

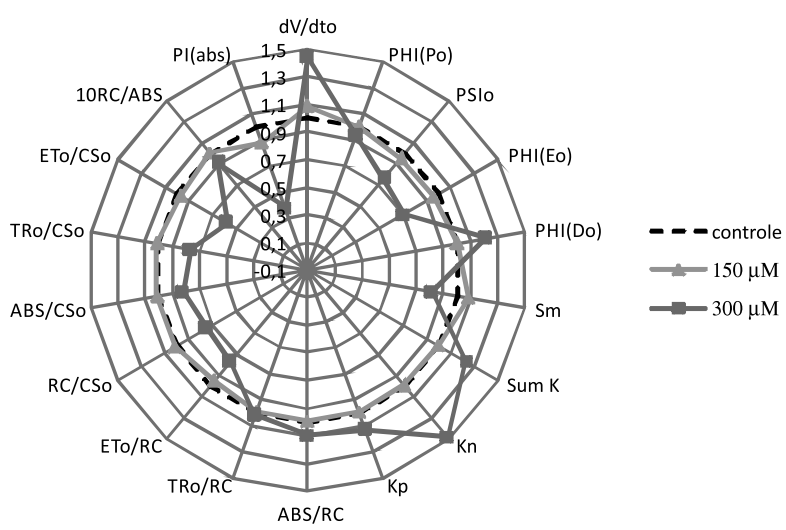

Figura 6. Bandas transientes da curva de emissão de fluorescência da Chl a (OJIP) para a substância $4(300 \mu \mathrm{M})$

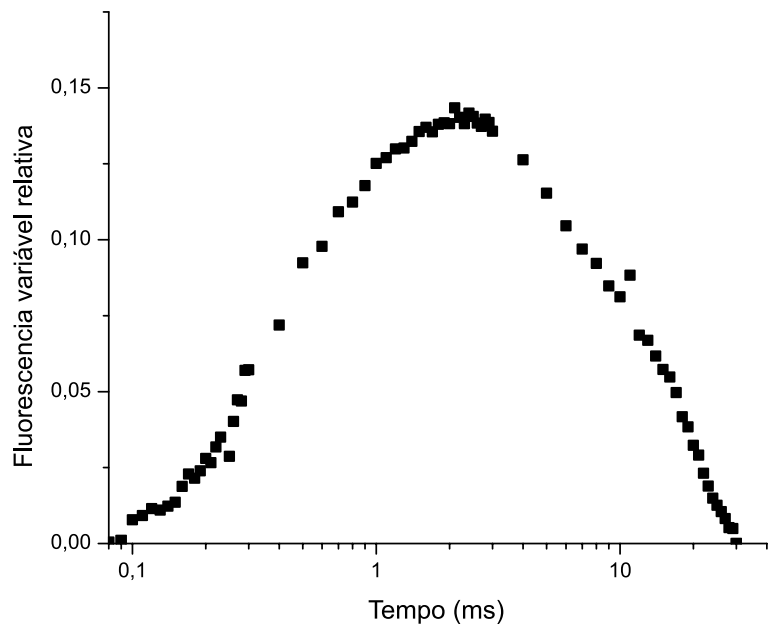

Figura 7. Bandas transientes da curva de emissão de fluorescência da Chl a (OJIP) para a substância 4 (4150 $\mu$ M; $300 \mu M)$

Os resultados experimentais sugerem que as cumarinas bergapteno (3) e chalepina (4) possuem as características exigidas de um bom inibidor da fotossíntese. Assim, esses resultados estimulam estudos de modificação estrutural ou desenvolvimento de uma biblioteca de furanocumarinas e di-hidrofuranocumarinas para análises de estrutura/atividade, o qual está em evolução.

Os ensaios de fluorescência da Chl $a$ foram realizados também com plantas da espécie L. perenne, utilizando as quatro substâncias avaliadas nas concentrações de 150 e $300 \mu \mathrm{M}$. Os resultados obtidos para este experimento após 24, 48 e 72 h de aplicação das soluções dos compostos não foram significativos. Sugere-se que, nessas concentrações, os compostos não conseguem ultrapassar as barreiras naturais (paredes, membranas celulares, etc.), das plantas até chegar aos tilacoides, no cloroplasto. Como os resultados não foram significativos, os gráficos não são apresentados neste trabalho.

\section{AGRADECIMENTOS}

A autora O. M. Sampaio agradece à FAPESP pela bolsa concedida, e à Capes, ao CNPq (INCT, 573742/2008-1) e à FAPESP (INCT, 08/57859-5) pelos apoios financeiros.

\section{REFERÊNCIAS}

1. Cobb, A. H.; Kirkwood, R. C.; Herbicides and their mechanisms of action, Sheffield Academic Press: Sheffield, 2000.

2. http://www.cnpma.embrapa.br/download/documentos_58.pdf, acessada em Outubro 2012.

3. Sing, S.; Debus, R. J.; Wydrzynski, T.; Hillier, W.; Philos. Trans. R. Soc. Lond. B Biol. Sci. 2008, 363, 1229.

4. Andreiadis, E. S.; Chavarot-Kerlidou, M.; Fontecave, M.; Artero, V.; Photochem. Photobiol. 2011, 87, 946.

5. Holub, O.; Seufferheld, M. J.; Gohlke, C.; Heiss, G. J.; Clegg, R. M.; J. Microsc. 2007, 226, 90.

6. Veiga, T. A. M.; Silva, S. C.; Archundia-Camacho, F.; Vieira, P. C.; Fernandes, J. B.; Rodrigues Fo, E.; Muller, M. W.; Silva, M. F. das G. F da; Hensenn, B. L.; J. Agric. Food Chem. 2007, 55, 4217.

7. Veiga, T. A. M.; Gonzalez-Vazquez, R.; Oiano Neto, J.; Silva, M. F. das G. F da; Diaz, B. K.; Hensenn, B. L.; Arc. Biochem. Biophys. 2007, 465, 38.

8. Strasser, R. J.; Srivastava, A.; Govindjee; Photochem. Photobiol. 1995, $61,32$.

9. Tsimilli-Michael, M.; Eggenberg, P.; Biró, B.; Köves-Pechy, K.; Vörös, I.; Strasser, R. J.; App. Soil Eco. 2000, 15, 169.

10. Oukarrom, A.; Strasser, R. J. S.; Afr. J. Bot. 2004, 70, 277.

11. Schanker, G.; Strasser, R. J.; Photosynth. Res. 2005, 84, 145.

12. Tsimilli-Michael, M.; Strasser, R. J.; Mycorrhiza: Genetics and Molecular Biology, Eco-function, Biotechnology, Eco-physiology, and Struture and Systematic Varma, A., $3^{\text {rd }}$ ed., Springer: Geneva, 2008.

13. Strasser, R. J.; Tsimilli-Michael, M.; Srivastava, A.; Chlorophyll Fluorescence: A Signature of Photosynthesis, $5^{\text {th }}$ ed., Springer: Netherlands, 2004.

14. Kruger, G. H. J.; Tsimilli-Michael, M.; Strasser, R. J.; Physiol. Plant. 1997, 101, 265.

15. Macias, M. L.; Rojas, I. S.; Mata, R.; Lotina-Hennsen, B.; J. Agric. Food Chem. 1999, 47, 2137.

16. Orlita, A.; Sidwa-Gorycka, M.; Kumirska, J.; Malinski, E.; Siedlecka, E. M.; Gajdus, J.; Lojkowska, E.; Stepnowski, P.; Biotechnol. Prog. 2008, 24, 128.

17. Aguilar, M. I.; Romero, M. G.; Chávez, M. I.; King-Díaz, B.; LotinaHennsen, B.; J. Agric. Food Chem. 2008, 56, 6994.

18. Torres-Romero, D.; King-Díaz, B.; Strasser, R. J.; Jiménez, I. A.; LotinaHennsen, B.; Bazzocchi, I. L.; J. Agric. Food Chem. 2010, 58, 10847.

19. Gonçalves, J. F. C.; Silva, C. E. M.; Guimarães, D. G.; Bernardes, R. S. A.; Acta Amaz. 2010, 40, 89. 